\title{
Financiële verslaggeving voor een efficiënte vermogensmarkt
}

\section{Inleiding}

In de afgelopen twee decennia is het paradigma van de efficiënte vermogensmarkt tot gemeengoed in de theorie van de financiering en in andere onderdelen van de economische wetenschap geworden. Daarnaast hebben zich gedurende die periode belangrijke ontwikkelingen in het denken over de verslaggeving door ondernemingen voltrokken. Het zal geen verbazing wekken dat de ontwikkelingen op beide terreinen elkaar wederzijds hebben beïnvloed. Enerzijds heeft men het verschijnen van het jaarverslag ${ }^{1}$ en het kennisnemen van specifieke gegevens daaruit gehanteerd als gebeurtenissen met behulp waarvan de efficiëntie van de vermogensmarkt werd onderzocht. Anderzijds is dikwijls - op basis van een veronderstelde marktefficiëntie de eventuele koersreactie van aandelen op de effectenbeurs beschouwd als een middel tot beoordeling van de informatieve waarde van het verslag en van onderdelen daarvan, alsmede van de doelmatigheid van de regelgeving op het gebied van de verslaggeving.

De vraag welke informatie-elementen in welke mate van detaillering in het financiële jaarverslag van de onderneming moeten worden opgenomen tracht men wel te beantwoorden door de informatiebehoeften van de verschillende groepen gebruikers van het verslag te analyseren. Men kan daarvoor de verschillende gebruikerscategorieën rechtstreeks ondervragen door middel van interviews of enquêtes (het zogenaamde gebruikersonderzoek ${ }^{2}$ ), maar ook - zoals hierboven werd aangegeven - bezien of en in hoeverre op de markt als gevolg van beschikbaar komende informatie een wijziging in de waardering van de onderneming optreedt (het marktonderzoek). De tweede benadering beperkt de relevante gebruikerscategorieën in feite tot de beleggers in de (gewone) aandelen van de onderneming. Ook in het onderstaande wordt deze beperking aangebracht.

In de tweede paragraaf van deze bijdrage wordt het begrip 'efficiëntie van de vermogensmarkt' nader aangeduid. In de derde paragraaf schenken wij aandacht aan het empirische onderzoek op het gebied van de relatie tussen marktefficiëntie en verslaggeving. Daarbij komen zowel de toetsing van de efficiëntie met behulp van gegevens uit de financiële verslaggeving, als de beoordeling van de informatieve waarde van deze gegevens door middel van het marktonderzoek aan de orde. Het is daarbij niet steeds noodzakelijk een strikt onderscheid te maken tussen de beide - zozeer samenhangende - 
probleemgebieden. Het empirische onderzoek op de beide terreinen is zeer omvangrijk. De lezer mag dan ook geen volledig overzicht ervan verwachten. In het bestek van dit artikel is het slechts mogelijk enkele van de belangrijkste bijdragen, die alle van Angelsaksische herkomst zijn, aan te duiden en enkele globale conclusies te trekken. In paragraaf 4 zullen tenslotte enkele afsluitende opmerkingen over de relatie tussen financiële verslaggeving en de efficiëntie van de vermogensmarkt worden gemaakt.

\section{Efficiëntie van de vermogensmarkt}

Er is sprake van een efficiënte vermogensmarkt indien alle beschikbare informatie op elk moment volledig in de prijzen van de op de markt verhandelde vermogensobjecten tot uitdrukking komt ${ }^{3}$ (Fama 1970, p. 383; 1976, p. 133) ${ }^{4}$. De beschikbare informatie komt - voorzover deze relevant is - ogenblikkelijk en op een juiste wijze in de evenwichtsprijzen op de markt tot uiting. Dit heeft tot gevolg dat het niet mogelijk is om op basis van kennis van bepaalde informatie-elementen transacties in de desbetreffende vermogensobjecten te verrichten en daarmede extra winsten te behalen (Jensen 1978, p. 96): de prijsvorming van aandelen en daarmee het totstandkomen van de opeenvolgende rendementen ervan geschiedt als een 'fair game'. Het onderzoek naar de vraag of er sprake is van efficiëntie van de vermogensmarkt heeft vrijwel uitsluitend op de markt van (officieel) op een effectenbeurs genoteerde aandelen betrekking gehad. De onderstaande uiteenzetting is dan ook op aandelen gericht.

De gegeven omschrijving van marktefficiëntie is te vaag en te algemeen om als toetsbare hypothese in het empirische onderzoek te dienen. Zowel de aard en de omvang van de relevante informatie, als het proces van prijsvorming op de vermogensmarkt moeten daartoe nader worden geconcretiseerd. In het verrichte onderzoek heeft men steeds deelverzamelingen van de beschikbare informatie in beschouwing genomen. Op basis van de inhoud van deze deelverzamelingen onderscheidde Fama (1970) een drietal varianten van het onderzoek naar de efficiëntie van de vermogensmarkt. In de zwakke variant is het onderzoek beperkt tot de informatie omtrent in het verleden waargenomen prijzen en rendementen van de aandelen. Uit vrijwel elk onderzoek ten aanzien van deze verzameling van informatie blijkt voor de onderzochte aandelenmarkten het bestaan van een grote mate van efficiëntie ${ }^{5}$. In de semi-stringente variant is het onderzoek gericht op alle voor het publiek beschikbare informatie. Naast onder meer dividendaankondigingen, aandelensplitsingen en stockdividenden, emissies en fusies behoort tot deze deelverzameling vooral de informatie, die in de financiële verslaggeving van ondernemingen is vervat. In paragraaf 3 wordt daaraan aandacht geschonken. Bij de stringente variant wordt ook de niet voor het publiek beschikbare informatie in de analyse betrokken. Het gaat hier om informatie bij functionarissen van professionele beleggingsinstellingen of van beleggingsbladen en om informatie bij 'insiders', bijvoorbeeld bestuurders van ondernemingen waarvan de aandelen op de beurs worden verhandeld. De uitkomsten van het onderzoek naar de efficiëntie van de markt 
ten aanzien van niet voor het publiek beschikbare informatie zijn uiteenlopend. Enerzijds wijst de analyse van de activiteiten van beleggingsinstellingen en van de adviezen van beleggingsbladen op een zekere mate van efficiëntie ten aanzien van deze soorten informatie, anderzijds maakt kennis van 'inside' informatie het volgens verschillende studies mogelijk extra winsten te behalen ${ }^{6}$.

Tussen informatieverzamelingen, die op de verschillende varianten betrekking hebben, valt geen scherpe grens te trekken. Het is bijvoorbeeld niet steeds zeker of een informatie-element voor het publiek beschikbaar, dan wel slechts in een kleine (?) kring van personen bekend is. Wel kan men vaststellen dat de tot de zwakke variant behorende informatie een onderdeel vormt van de informatie, die in de semi-stringente variant wordt onderzocht. Hetzelfde geldt voor de informatie van de semi-stringente variant ten opzichte van die van de stringente variant. In feite kan men ten aanzien van de in de verschillende varianten onderzochte informatie slechts van een graad van efficiëntie spreken. Keane (1983) duidt de genoemde varianten dan ook als niveaus van efficiëntie aan. Beaver (1981b) wijst er op dat men een onderscheid tussen systeem- en signaalefficiëntie moet maken. De eerste heeft betrekking op elk mogelijk signaal uit een informatiesysteem, de laatste slechts op een afzonderlijk signaal dat wordt waargenomen. Het empirische onderzoek heeft steeds op signaalefficiëntie betrekking.

Het onderzoek van de marktefficiëntie vergt inzicht in het op de markt plaatsvindende prijsvormingsproces. Dit proces kan als volgt worden beschreven ${ }^{7}$. Op basis van de aan het begin van een periode (op tijdstip t) beschikbare informatie maken de verschillende marktpartijen zich een voorstelling van de kansdichtheidsfunctie van de aan het einde van de periode (op tijdstip $t+1$ ) voor het vermogensobject geldende prijs en van de omvang van de eventuele gedurende de periode daarop verrichte uitkeringen (bijvoorbeeld dividend). Uit dit beeld van de op tijdstip $t+1$ mogelijke waarden van de beide variabelen voor de verschillende aandelen en de daarbij behorende simultane kansen leidt de markt de op tijdstip t geldende evenwichtsprijzen van de aandelen af.

De prijsvorming geschiedt op een zodanige wijze dat de verwachtingswaarde van het rendement voor elk vermogensobject een positieve waarde heeft. Onder het gedurende periode $t$ op een aandeel behaalde rendement verstaan wij de grootheid $\left(\mathrm{P}_{t_{+1}}-\mathrm{P}_{\mathrm{t}}\right) / \mathrm{P}_{\mathrm{t}}{ }^{8}$. Hierbij stellen $\mathrm{P}_{\mathrm{t}+1}$ respectievelijk $\mathrm{P}_{\mathrm{t}}$ de prijs van het aandeel aan het einde respectievelijk aan het begin van periode $t$ voor. Eventuele uitkeringen op het aandeel worden geacht in $P_{t_{+1}}$ te zijn begrepen.

Op basis van het voorgaande kan thans worden vastgesteld wanneer aan een signaal uit een informatiesysteem informatieve waarde kan worden toegekend. Dit is het geval indien er als gevolg van het ontvangen signaal een wijziging komt in de simultane kansdichtheidsfunctie van de op tijdstip $t+1$ geldende prijzen. Anders gezegd: de voor de marktprijzen geldende kansdichtheidsfuncties voor de prijzen op tijdstip $t+1$ worden vervangen door de voorwaardelijke functies, die gelden bij kennis van het ontvangen 
informatiesignaal. In beginsel leidt zulks tot een wijziging van de op tijdstip t vastgestelde prijs van het vermogensobject ${ }^{9}$.

De informatieve waarde van informatie-elementen kan - zo blijkt uit het voorgaande - worden vastgesteld door het analyseren van de prijswijziging, die op tijdstip $t$ als gevolg van het ter beschikking komen van een informatiesignaal optreedt. Een probleem bij deze analyse ligt in het feit dat een prijswijziging op dat moment ook door andere factoren kan worden veroorzaakt. Men dient zich dan ook een beeld te vormen van de prijs, die zonder het beschikbaar komen van de desbetreffende informatie op tijdstip t zou zijn opgetreden. In het empirische onderzoek specificeert men daartoe een model, dat de totstandkoming van de evenwichtsprijzen op de vermogensmarkt weergeeft. In het kader van de semi-stringente variant gebruikt men daarvoor dikwijls een twee-parameter-model, te weten één van de versies van het zogenaamde 'capital asset pricing model' (CAPM) of het marktmodel. Ter toelichting daarvan diene het volgende. Voor een uitvoerige uiteenzetting van deze modellen en van de veronderstellingen waarop zij berusten wordt naar de bestaande literatuur (bijvoorbeeld Bouma, 1980) verwezen.

De door Black (1972) ontwikkelde variant van het CAPM luidt

$$
\begin{aligned}
\mathrm{E}\left(\tilde{\mathrm{r}}_{\mathrm{it}}\right) & \left.=\mathrm{E}\left(\tilde{\mathrm{r}}_{\mathrm{zt}}\right)+\left[\mathrm{E}\left(\tilde{\mathrm{r}}_{\mathrm{mt}}\right)-\mathrm{E} \tilde{\mathrm{r}}_{\mathrm{zt}}\right)\right] \beta_{\mathrm{it}} \\
& =\mathrm{E}\left[\tilde{\mathrm{r}}_{\mathrm{it}} \mid \mathrm{E}\left(\tilde{\mathrm{r}}_{\mathrm{zt}}\right), \mathrm{E}\left(\tilde{\mathrm{r}}_{\mathrm{mt}}\right), \beta_{\mathrm{it}}\right]
\end{aligned}
$$

waarin

$\tilde{\mathbf{r}}_{\mathrm{it}}=$ het gedurende periode $\mathrm{t}$ op vermogensobject $\mathrm{i}^{10}$ behaalde rendement;

$\tilde{\mathbf{r}}_{\mathrm{zt}}=$ het gedurende periode $\mathrm{t}$ op een vermogensobject $(\mathrm{z})$ met een minimale variantie van het rendement en $\beta_{z t}=0$, behaalde rendement;

$\tilde{\mathbf{r}}_{\mathrm{mt}}=$ het gedurende periode $\mathrm{t}$ op de marktportefeuille $(\mathrm{m})$ behaalde rendement;

$\beta_{i t}=\operatorname{cov}\left(\tilde{r}_{i t}, \tilde{r}_{m t}\right) / \operatorname{var}\left(\tilde{r}_{m t}\right)=$ het relatieve risico van vermogensobject $i$ ten opzichte van dat van de marktportefeuille (het zogenaamde systematische risico).

Het symbool E geeft de verwachtingswaarde van de desbetreffende stochastische variabelen weer.

Gegeven de verwachtingswaarden van $\tilde{\mathrm{r}}_{\mathrm{tt}}$ en $\tilde{\mathbf{r}}_{\mathrm{mt}}$ en de waarde van $\beta_{\mathrm{it}}$ geldt

$\tilde{\varepsilon}_{i t}=\overline{\mathbf{r}}_{i t}-\mathrm{E}\left[\tilde{r}_{\mathrm{it}} \mid \mathrm{E}\left(\tilde{\mathrm{r}}_{\mathrm{tt}}\right), \mathrm{E}\left(\tilde{\mathrm{r}}_{\mathrm{mt}}\right), \beta_{\mathrm{it}}\right]$

Bij een efficiënte vermogensmarkt is $\tilde{\varepsilon}_{i t}$ een 'fair game' variabele:

$\mathrm{E}\left(\tilde{\boldsymbol{\varepsilon}}_{\mathrm{it}}\right)=0$

en

$\mathrm{E}\left(\tilde{\varepsilon}_{\mathrm{it}} \mid \tilde{\varepsilon}_{\mathrm{it}-1}, \tilde{\varepsilon}_{\mathrm{it}-2}, \ldots \ldots \ldots, \tilde{\varepsilon}_{\mathrm{it}-\mathrm{n}}\right)=0$ 
Veelal wordt verondersteld dat $\tilde{\varepsilon}_{\text {it }}$ normaal verdeeld is. Wanneer men voorts aanneemt dat in vergelijking (2) via $\mathrm{E}\left(\tilde{\mathrm{r}}_{\mathrm{zt}}\right), \mathrm{E}\left(\tilde{\mathrm{r}}_{\mathrm{mt}}\right)$ en $\beta_{\mathrm{it}}$ de invloed van alle reeds bekende informatie tot uiting komt, geeft de geschatte waarde van $\tilde{\varepsilon}_{\text {it }}$ de invloed op de prijsvorming van nieuwe op tijdstip $t$ ter beschikking komende informatie weer. Wanneer de rendementen van alle vermogensobjecten meerdimensionaal normaal verdeeld zijn geldt voor elk aandeel i als statistische eigenschap

$\mathrm{E}\left(\tilde{\mathrm{r}}_{\mathrm{it}} \mid \mathrm{r}_{z t}, \mathrm{r}_{\mathrm{mt}}\right)=\gamma_{\mathrm{it}}+\delta_{\mathrm{it}} \mathrm{r}_{\mathrm{zt}}+\beta_{\mathrm{it}} \mathrm{r}_{\mathrm{mt}}$

Bij de voor het c.a.p.m. gemaakte veronderstellingen is $\gamma_{i t}=0$ en $\delta_{i t}=(1-$ $\beta_{\mathrm{it}}$ ), waardoor geldt

$\mathrm{E}\left(\boldsymbol{\beta}_{\mathrm{it}} \mid \mathrm{r}_{\mathrm{zt}}, \mathrm{r}_{\mathrm{mt}}\right)=\left(1-\beta_{\mathrm{it}}\right) \mathrm{r}_{\mathrm{zt}}+\beta_{\mathrm{it}} \mathrm{r}_{\mathrm{mt}}$

Veronderstelt men voorts dat var $\left(\tilde{r}_{\mathrm{zt}}\right)=0$ dan stelt $\mathbf{r}_{\mathrm{zt}}$ een vaste risicoloze rentevoet voor en gaat het model over in de bekende Sharpe-variant van het c.a.p.m. Het valt tenslotte eenvoudig in te zien dat vergelijking (6) een speciale vorm is van het zogenaamde marktmodel, waarin de relatie tussen $r_{i t}$ en $r_{m t}$ als volgt wordt weergegeven

$\tilde{\mathrm{r}}_{\mathrm{it}}=\alpha_{\mathrm{it}}+\beta_{\mathrm{it}} \mathrm{r}_{\mathrm{mt}}+\tilde{\varepsilon}_{\mathrm{it}}$

Door schatting van de parameters $\alpha_{\mathrm{i}}$ en $\beta_{\mathrm{i}}$ kan men voor verschillende perioden de geschatte waarde van het residu $\tilde{\varepsilon}_{i t}$ vaststellen. Bij een efficiënte markt geldt - zoals wij zagen $-\mathrm{E}\left(\tilde{\varepsilon}_{\mathrm{it}}\right)=0$.

Bij de semi-stringente variant van het onderzoek naar de efficiëntie van de markt wordt vrijwel steeds in enigerlei vorm gebruik gemaakt van de methode van het schatten van de waarden van de residuvariabelen $\tilde{\varepsilon}_{i t}$, teneinde te bepalen of en in welke mate de markt op het ter beschikking komen van informatiesignalen reageert. Het is thans duidelijk dat men hierbij in feite steeds twee hypothesen toetst: de efficiëntie van de markt èn de juiste specificatie van het prijsvormingsmodel. Wanneer bij het ter beschikking komen van nieuwe informatie de waarde(n) van de residuvariabelen significant van nul verschillen kan men aannemen dat de desbetreffende signalen informatieve waarde bezitten. Wanneer de aanpassing van de prijzen in dat geval ogenblikkelijk plaatsvindt en niet met vertraging geschiedt, kan men tevens concluderen dat de markt efficiënt is. Reageert de prijs daarentegen niet op de nieuwe informatie, dan kan men stellen dat deze informatie geen waarde heeft of dat zij op de efficiënte markt reeds in het prijsniveau is verwerkt. $\mathrm{Bij}$ al deze conclusies gaat men evenwel uit van de veronderstelling dat het prijsvormingsmodel juist is gespecificeerd.

Het voorgaande doet zien dat aan het statistische onderzoek op ons terrein tal van statistische problemen verbonden zijn. Wij gaan echter op de onderzoeksmethoden en -problemen niet verder in en beperken ons hierna tot het weergeven van enkele resultaten van het verrichte onderzoek. 


\section{Enkele uitkomsten van het onderzoek}

Het marktonderzoek en het onderzoek naar de marktefficiëntie met behulp van jaarverslagen hebben betrekking op twee gebieden: de gepubliceerde winstcijfers en de bij de verslaggeving gebruikte methoden van winstbepaling en balanswaardering ('accounting methods'). In beide onderzoeksterreinen wordt vrijwel steeds van het hierboven beschreven model gebruik gemaakt, waardoor de uitkomsten ervan aan het voorbehoud van een juiste specifikatie van het model zijn onderworpen. Zoals gesteld zien wij echter af van een kritische beschouwing van de gehanteerde onderzoekmethoden. In het kader van dit bijzondere nummer van het MAB is een globale weergave van de belangrijkste resultaten van het onderzoek belangwekkender dan een aantal kritische kanttekeningen daarover.

\subsection{Winstcijfers}

Aan het einde van de zestiger jaren werd door Benston (1967), Beaver (1968) en door Ball en Brown (1968) aandacht besteed aan de relatie tussen de gepubliceerde jaarlijkse winstcijfers en het koersgedrag van aandelen. Met name het artikel van Ball en Brown heeft grote bekendheid verkregen. Deze auteurs gaan uit van de gedachte dat de markt een verwachting heeft omtrent de aan te kondigen jaarwinst. Slechts wanneer de gepubliceerde winst afwijkt van deze verwachting zal een reactie in de prijs van de aandelen optreden. Ten einde de winstverwachting van de markt te bepalen, ontwikkelden Ball en Brown een model waarmee de verwachte winst van een onderneming wordt gerelateerd aan de in eenzelfde periode behaalde gemiddelde winst van de op de markt genoteerde ondernemingen. Ook andere winstmodellen zijn later door verschillende auteurs getoetst. Ball en Brown onderzochten de winstaankondigingen van 261 op de New York Stock Exchange genoteerde aandelen voor de periode 1957-1965. De conclusie van het onderzoek was dat de publicatie van de jaarlijkse winstcijfers informatieve waarde heeft. De koers reageert op onverwachte winstveranderingen. Tevens werd echter vastgesteld dat de koersontwikkeling gedurende twaalf aan de publicatie voorafgaande maanden in overeenstemming was met de richting van de winstafwijking ten opzichte van de verwachting. Ongeveer $85 \%$ van de koersbeweging was op het moment van publicatie reeds in de prijs verwerkt.

Ball en Brown concludeerden op basis van dit resultaat tot marktefficiëntie: de markt verwerkt het beschikbaar komen van informatie op een juiste wijze. Vóórdat de informatie over de winst in de jaarcijfers ter beschikking komt heeft de markt reeds andere bronnen van informatie gebruikt. Soortgelijke conclusies werden ook voor andere effectenbeurzen getrokken. Beaver (1968) onderzocht ook het aantal transacties, dat na publicatie van het verslag op de effectenbeurs werd uitgevoerd en concludeerde aan de hand daarvan eveneens tot een informatieve waarde van het jaarverslag. Interessant is het ook dat er een relatie bestaat tussen de omvang van de onverwachte winst en de omvang van de daarmee gepaard gaande koersmutatie (Beaver, Clarke en Wright, 1979). 
Het is overigens niet verwonderlijk dat op het moment van publicatie van het jaarverslag reeds veel informatie in de koersen is verwerkt. De informatieve waarde van gedurende het verslagjaar gepubliceerde kwartaalcijfers (Brown en Kennelly, 1972; Jordan, 1973), indicaties omtrent de winst door functionarissen van de onderneming (Foster, 1973; Patell, 1976; Gonedes, Dopuch en Penman, 1976), winstvoorspellingen door beleggingsanalysten (Givoly en Lakonishok, 1979) en van de winstcijfers van andere ondernemingen in de branche (Foster, 1981) is - althans voor de onderzochte aandelenmarkten - genoegzaam aangetoond.

In het algemeen wijzen de genoemde studies ook in de richting van efficiëntie van de markt. Soms is het evenwel moeilijk hiervan een duidelijk beeld te verkrijgen. Dikwijls werkt men met rendementen, die over perioden van een maand of een week zijn berekend. Om echter een juist inzicht in de snelheid van de prijsaanpassing te verkrijgen moet men met dagrendementen werken. In een aantal gevallen werd waargenomen, dat de prijsaanpassing zich na het beschikbaar komen van informatie met enige vertraging voltrekt. In een artikel uit 1978 noemt Ball (1978) een aantal studies, waarin een aantal anomalieën ten opzichte van de marktefficiëntie voorkomt ${ }^{11}$, doch hij meent dat deze anomalieën zijn toe te schrijven aan onvolkomenheden in het bij de toetsing gebruikte tweeparametermodel ${ }^{12}$. Van de in jaarverslagen gepubliceerde cijfers is slechts de winst aan onderzoek onderworpen geweest. Andere cijfers (bijvoorbeeld omzetten en kosten) zijn nog niet op hun informatieve waarde getoetst. Wel werd door Gonedes (1974) de informatieve betekenis van een aantal aan het jaarverslag ontleende financiële ratios aangetoond. Ook is de relatie tussen in het jaarverslag verstrekte gegevens en de hoogte van het systematische risico (de bèta) van aandelen aannemelijk gemaakt (onder meer door Beaver, Kettler en Scholes, 1970). Veel aandacht is daarnaast besteed aan wijzigingen in de methoden van winstbepaling en balanswaardering.

\subsection{Wijzigingen in 'accounting methods'}

Onderzoek naar de invloed van wijzigingen in de methoden van winstberekening en balanswaardering op de prijs van aandelen geschiedde in eerste instantie veelal in het kader van de toetsing van de efficiëntie van de markt. Archibald (1972) onderzocht de reactie van de aandelenkoers op wijzigingen van de afschrijvingsmethode in de bedrijfseconomische - niet in de fiscale jaarrekening ${ }^{13}$. Ball (1972) bestudeerde het effect van 267 'accounting changes'. Kaplan en Roll (1972) bezagen het effect van verschillende wijzen van verwerking van de investeringsaftrek in de jaarrekening en van wijzigingen in de afschrijvingsmethoden. Sunder (1975) ten slotte bestudeerde de gevolgen van veranderingen in de wijze van voorraadwaardering (FIFO, LIFO). De algemene conclusie van het genoemde empirische onderzoek luidde dat de markt efficiënt is in die zin dat veranderingen in de verslaggevingsmethoden, die geen werkelijke economische betekenis (bijvoorbeeld door een wijziging in de cash flow) hebben, door de markt worden genegeerd. De markt ziet er door heen (you cannot fool the market!) ${ }^{14}$. De laatste tijd is de aard van het onderzoek enigszins verschoven. Uitgaande 
van efficiëntie van de markt tracht men de betekenis van bepaalde 'accounting'-methoden - mede met het oog op de regelgeving - te analyseren. Van belang is in dit verband dat veranderingen in de methoden van verslaggeving, die ogenschijnlijk geen economische betekenis hebben, toch reële economische effecten kunnen vertonen. Zo kunnen veranderingen in de methoden een signaal vormen voor een wijziging in de verwachtingen van de ondernemingsleiding. Daarnaast kunnen ook mutaties in de cash flow van een verandering van methode het gevolg zijn (bijvoorbeeld door kosten verbonden aan de verslaggeving en de controle, alsmede aan het afsluiten van contracten, die op informatie uit het jaarverslag berusten) ${ }^{15}$. In navolging van de door Watts en Zimmermann (1978) ontwikkelde theorie verschuift de vraagstelling naar de oorzaken van bepaalde wijzen van winstbepaling en van het optreden van prijseffecten bij wijzigingen daarin. Een goed voorbeeld van deze benaderingswijze is de discussie, die zich in de Amerikaanse literatuur heeft afgespeeld omtrent de (voorgenomen) veranderingen in de voorgeschreven wijze van verwerking van boor- en exploratiekosten bij olie- en gasmaatschappijen (bijvoorbeeld Larcker en Revsine, 1983). Voor Nederlandse lezers is in dit verband ook het onderzoek naar de informatieve waarde van de vervangingswaarde in de jaarrekening interessant (zie bijvoorbeeld Watts en Zimmermann, 1980 en Beaver, Griffin en Landsman, 1982). Ten slotte wijzen wij er op dat wijzigingen in verslaggevingsmethoden een geheel verschillende informatieve waarde lijken te bezitten al naar gelang de wijziging vrijwillig wordt aangebracht dan wel wordt voorgeschreven (Harrison, 1977) ${ }^{16}$.

\section{Conclusie en afsluitende opmerkingen}

Informatie in jaarverslagen - zo kan uit het voorgaande worden geconcludeerd - heeft voor de belegger in gewone aandelen informatieve waarde. Weliswaar is een groot deel van de in het verslag beschikbaar komende informatie reeds in de koers van het aandeel verdisconteerd, maar toch wordt op het moment van de publicatie van het verslag nieuwe informatie bekend. Dit blijkt uit het feit dat de prijzen van aandelen op de publicatie reageren ${ }^{17}$. Deze reactie is veelal binnen korte tijd ten einde, waardoor althans in de onderzochte markten en enkele anomalieën daargelaten marktefficiëntie kan worden vastgesteld.

Welke lessen kunnen nu uit het vermelde onderzoek voor de verslaggeving worden getrokken? In de eerste plaats moet worden vastgesteld dat de informatieve waarde van het verslag niet voor alle beleggers behoeft te gelden. Marktefficiëntie wordt reeds verkregen indien slechts enkele (veelal professionele) beleggers op de beschikbaar komende informatie reageren. Het verslag kan zich vanuit dat gezichtspunt - voorzover het ondernemingen betreft waarvan de aandelen op een efficiënte markt worden genoteerd dan ook richten op die 'sophisticated' beleggers, die door hun analyses de efficiëntie van de markt bewerkstelligen. Een snelle informatieverstrekking is daarbij van groot belang. Overigens moet daarbij worden bedacht dat het verslag ook andere gebruikersgroepen dient. Het blijft een open vraag in 
hoeverre de huidige wijze van verslaggeving aan de informatiebehoeften van alle verschillende gebruikerscategorieën tegemoet komt. Wellicht is een meer gerichte informatieverschaffing gewenst. Ook aan de behoeften van de betrekkelijk grote groep gebruikers, die bij enquêtes zegt het jaarverslag slechts voor 'algemene oriëntatie' te lezen, moet in dat verband aandacht worden besteed.

Een tweede les voor de verslaggeving betreft de inhoud van de te verstrekken informatie. In het verleden is in de theorie veel gediscussieerd over de 'juiste' wijze van verslaggeving. Het verrichte onderzoek geeft aanleiding de betekenis daarvan enigszins te relativeren. De bruikbaarheid van de verstrekte informatie voor de beleggers kan thans mede worden bepaald door het marktonderzoek, dat de effecten van informatie-elementen op de aandelenprijzen bestudeert. Men behoeft niet zover te gaan de wenselijkheid van de publicatie van informatie slechts door de reactie van de aandelenkoers te doen bepalen ${ }^{18}$. Wel kan het marktonderzoek - naast het gebruikersonderzoek - een indicatie geven over het feit of en in hoeverre bepaalde informatie-elementen door de beleggers worden gebruikt en of aan bepaalde methoden van winstbepaling en balanswaardering informatieve betekenis toekomt. In die zin zullen in de toekomst verslaggeving en marktefficiëntie elkaar blijvend beïnvloeden.

\footnotetext{
Noten

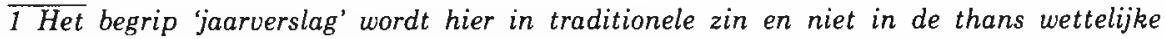
betekenis van directieverslag gebruikt.

2 Vergelijk Schreuder (1982). Zie voor enkele toepassingen van deze benadering in ons land Klaassen en Schreuder (1980) en Ankum en Dekker (1980, 1983).

3 Beaver (1981a, p. 147) definieert marktefficiëntie ten opzichte van een informatiesysteem als de omstandigheid '... that security prices act as if everyone observes the information system'. Zie voor een commentaar op deze definitie Ankum en Dorsman (1983).

4 Van publicaties, die niet in de literatuurlijst zijn opgenomen, is de vindplaats vermeld in Foster (1978).

5 Zie voor samenvattende overzichten van het op dit gebied verrichte onderzoek onder meer Fama (1970), Lev (1974), Dyckman, Downes en Magee (1975), Eijgenhuijsen (1977), Firth (1977) en Keane (1983). Voor de Amsterdamse Effectenbeurs werd op dit terrein onderzoek verricht door Theil en Leenders (1965), Solnik (1973), Ankum en Dorsman (1983, 1984a, 1984b), Dorsman en De Gooijer (1982) en door De Gooijer (1984).

6 Vergelijk voor een overzicht van het onderzoek op dit terrein de in noot 5 genoemde samenuattende publicaties. Zie voor de Amsterdamse Effectenbeurs Dorsman en De Gooijer (1984).

7 Zie voor een uitgebreidere beschrijuing Ankum en Dorsman (1983, hoofdstuk 2).

$8 P_{t+1}$ is zonodig gecorrigeerd voor mutaties in het geplaatste aandelenkapitaal. Dikwijls wordt in het empirische onderzoek het rendement ook op basis van continue interestrekening gedefinieerd als $\ln \left(P_{t+1} / P_{\downarrow}\right)$.

9 Wij laten daarbij de mogelijkheid dat voor alle marktpartijen de marginale en de voorwaardelijke kansdichtheidsfunctie samenvallen buiten beschouwing.

10 Het vermogensobject kan vanzelfsprekend ook een portefeuille zijn. Gemakshalve spreken wij slechts over een vermogensobject. De tilde (') geeft aan dat het om een stochastische grootheid gaat.

11 Zie daarvoor de literatuuropgave bij Ball (1978).

12 Zie echter Basu (1978), Brown (1978) en Watts (1978).

13 Vergelijk ook Beaver en Dukes (1972, 1973).

14 Een soortgelijke conclusie trekken Cassidy (1976) voor de verwerking van de investeringsaftrek in de jaarrekening en Hong, Kaplan en Mandelker (1978) voor de verwerking van een aandelenfusie.

15 Zie Holthausen en Leftwich (1983) en de daar genoemde literatuur.
} 
16 Hierboven noemden wij slechts de ons inziens belangrijkste literatuur op het onderhavige terrein. Zie voor een vollediger overzicht de in noot 5 genoemde - samenvattende-publicaties, alsmede Foster (1978) en Beaver (1981).

17 Uiteraard heeft ook een verslag dat de verwachtingen van de markt bevestigt informatieve waarde. Het is evenwel niet mogelijk deze met behulp van de beschreven methode te meten. 18 Zo wijzen May en Sundem (1973) er op dat sommige (nuttige) informatie niet in de koers tot uiting komt. Zie ook Gonedes en Dopuch (1974).

\section{Literatuur}

Ankum, L. A. en H. C. Dekker, 1980, Aandeelhouder en jaarverslag, in: Financiering en Belegging, Stand van zaken anno 1980, Leiden 1980.

Ankum, L. A. en H. C. Dekker, 1983, Investors and the Corporate Report: Some Preliminary Findings, Universiteit van Amsterdam, Research Memorandum RM 8311, 1983.

Ankum, L. A. en A. B. Dorsman, 1983, De efficiëntie van de Amsterdamse Effectenbeurs, Universiteit van Amsterdam, Economische Monografieën No 2, 1983.

Ankum, L. A. en A. B. Dorsman, 1984a, De herschikkingsstrategie en de efficiëntie van de Amsterdamse Effectenbeurs: een simulatie, in: Het Financiële Systeem, Leiden/Antwerpen, 1984.

Ankum, L. A. en A. B. Dorsman, 1984b, De efficiëntie van de Amsterdamse Effectenbeurs: Resultaten van de filterstrategie, Maandblad voor Accountancy en Bedrijfshuishoudkunde, mei 1984.

Archibald, T. R., 1972, Stock Market Reaction to the Depreciation Switch-Back, The Accounting Review, January 1972.

Ball, R., 1978, Anomalies in Relationships between Securities: Yields and Yield Surrogates, Journal of Financial Economics, June/September 1978.

Basu, S., 1978, The Effect of Earnings Yield on Assessments of the Association between Annual Accounting Income Numbers and Security Prices, The Accounting Review, July 1978.

Beaver, W. H., R. Clarke en W.F. Wright, 1979, The Association between Unsystematic Security Returns and the Magnitude of Earnings Forecast Errors, Journal of Accounting Research, Autumn 1979.

Beaver, W. H., 1981a, Financial Reporting: An Accounting Revolution, Englewood Cliffs, N. J., 1981.

Beaver, W. H., 1981b, Market Efficiency, The Accounting Review, January 1981.

Beaver, W. H., P.A. Griffin en W. R. Landsman, 1982, The Incremental Information Content of Replacement Cost Earnings, Journal of Accounting and Economics, July 1982.

Bouma, J. L., 1980, De theorie van de financiering van ondernemingen, Den Haag, 2e druk, 1980.

Brown, S. L., 1978, Earnings Changes, Stock Prices, and Market Efficiency, The Journal of Finance, March 1978.

Dorsman, A. B. en J. G. de Gooijer, 1982, Het verloop van de koersen op de Amsterdamse Effectenbeurs en de random walk hypothese, Bedrijfskunde, 1982.

Dorsman, A. B. en J. G. de Gooijer, 1984, De stringente variant van de efficiënte markthypothese en de Amsterdamse Effectenbeurs, Bedrijfskunde, 1984.

Dyckman, Th. R., D. H. Downes en R. P. Magee, 1975, Efficient Capital Markets and Accounting: A critical analysis, Englewood Cliffs, 1975.

Eijgenhuijsen, H. G., 1977, Risico en rendement van aandelenportefeuilles, Leiden 1977.

Foster, G., 1978, Financial Statement Analysis, Englewood Cliffs 1978.

Foster, G., 1981, Intra-industry Information Transfers Associated with Earnings Releases, Journal of Accounting and Economics, December 1981.

Givoly, D. en J. Lakonishok, 1979, The Information Content of Financial Analysts' Forecasts of Earnings: Some Evidence on Semi-Strong Inefficiency, Journal of Accounting and Economics, December 1979.

Gooijer, J. G. de, 1984, Contributions to Univariate Time Series Analysis with an Application to Dutch Stock Market Prices, 's-Gravenhage 1984.

Harrison, T., 1977, Different Market Reactions to Discretionary and Nondiscretionary Accounting Changes, Journal of Accounting Research, Spring 1977.

Holthausen, R. W. en R. W. Leftwich, 1983, The Economic Consequences of Accounting Choice: Implications of Costly Contracting and Monitoring, Journal of Accounting and Economics, August 1983. 
Jensen, M. C., 1978, Some Anomalous Evidence Regarding Market Efficiency, Journal of Financial Economics, June/September 1978.

Jordan, R., 1973, An Empirical Investigation of the Adjustment of Stock Prices to New Quarterly Earnings Information, Journal of Financial and Quantitative Analysis, September 1973.

Keane, S. M., 1983. Stock Market Efficiency: Theory, Evidence and Implications, Oxford, 1983.

Klaassen, J. en H. Schreuder, 1980, Het financiële jaarverslag van ondernemingen: Een onderzoek onder gebruikers, Leiden/Antwerpen, 1980.

Larcker, D. H. en L. Revsine, 1983, The Oil and Gas Controversy: An Analysis of Economic Consequences, The Accounting Review, October 1983.

Schreuder, H., 1982, Over relevantie van informatie uit jaarverslagen, Bedrijfskunde, 1982.

Solnik, B. H., 1973, Note on the Validity of the Random Walk for European Stock Prices, The Journal of Finance, December 1973.

Theil, H. en C. T. Leenders, 1965, Tomorrow on the Amsterdam Stock Exchange, Journal of Business, 1965.

Watts, R. L., 1978, Systematic 'Abnormal' Returns after Quarterly Earnings Announcements, Journal of Financial Economics, June/September 1978.

Watts, R. L. en J. L. Zimmerman, 1978, Towards a Positive Theory of Determination of Accounting Standards, The Accounting Review, January 1978.

Watts, R. L. en J. L. Zimmerman, 1980, On the Irrelevance of Replacement Cost Disclosures for Security Prices, Journal of Accounting and Economics, August 1980. 